\title{
BIFUNCTIONAL CATALYSTS FOR THE SELECTIVE CATALYTIC REDUCTION OF NO BY HYDROCARBONS
}

\author{
Michael K. Neylon, Mario J. Castagnola, A. Jeremy Kropf, and Christopher L. Marshall \\ Chemical Engineering Division, Argonne National Laboratory, Argonne, IL.
}

\begin{abstract}
Novel bifunctional catalysts combining two active phases, typically Cu-ZSM-5 and a modifier, were prepared and tested for the selective catalytic reduction of nitrogen oxides using propylene in order to overcome the hindering effects of water typically seen for single-phase catalysts such as Cu-ZSM-5. The catalysts were made by typical preparation techniques, but parameters could be varied to influence the catalyst. The physical characterization of the materials showed that the modification phase was added strictly to the external surface of the zeolite without hindering any internal surface area. Chemical characterization by temperatureprogrammed reactions, DRIFTS and x-ray absorption spectroscopy indicated strong interaction between the two phases, primarily producing materials that exhibited lower reduction temperatures. Two improvements in NOx reduction activity (1000 ppm NO, $1000 \mathrm{ppm} \mathrm{C}_{3} \mathrm{H}_{6}, 2 \% \mathrm{O}_{2}$, $30,000 \mathrm{hr}^{-1} \mathrm{GHSV}$ ) were seen for these catalysts compared with Cu-ZSM-5: a lower temperature of maximum NOx conversion activity (as low at $250^{\circ} \mathrm{C}$ ), and an enhancement of activity when water was present in the system. The use of a second phase provides a way to further tune the properties of the catalyst in order to achieve mechanistic conditions necessary to maximize NOx remediation.
\end{abstract}

\section{INTRODUCTION}

Nitrogen oxide emissions from combustion sources, including chemical and power plants and gasoline and diesel-based engines, have become an increasingly important concern over the last several decades, as NOx has been shown to be a major pollutant and a contributor to low-level smog and acid rain. Governments worldwide are issuing new restrictions on NOx emissions over the next decade, which has driven several advances in NOx abatement technology primarily under lean-burn conditions. The current industrial solution is the use of ammonia in the selective catalytic reduction of $\mathrm{NOx}\left(\mathrm{NH}_{3}-\mathrm{SCR}\right)$. While this method is effective at reducing NOx emissions, there are two concerns with the use of ammonia. First, it must be available, either from a storage tank or generated in situ from urea. While stationary plants can add such capacities, neither solution is ideal from a transportation standpoint. The second concern with $\mathrm{NH}_{3}$-SCR is the slippage of unreacted ammonia to the atmosphere. Ammonia is also a hazardous chemical, and while a single $\mathrm{NH}_{3}$-SCR unit can keep the slippage to less than 5ppm, the large number of potential $\mathrm{NH}_{3}$-SCR units expected to be installed may lead to a large increase in $\mathrm{NH}_{3}$ pollution.

An alternate method has been proposed in the use of a light hydrocarbon, such as propene, propane, or methane, in place of the ammonia as the reductant during selective catalytic reduction (HC-SCR). Hydrocarbons can be provided from the fuel source, thus requiring no additional storage, and hydrocarbon slippage is not as drastic an issue as with ammonia slippage, though unconverted hydrocarbons can be oxidized easily to clean products if needed. A large body of catalysts has been found to work for HC-SCR, but primarily metalexchanged zeolites appear to be the most promising, as first reported by Iwamoto [1]. While these catalysts are very active and selective for $\mathrm{HC}$ SCR under lean conditions, they exhibit poor behavior in the presence of water, which is nearly always present from a combustion process. This hydrothermal deactivation is attributed to either dealumination of the zeolite, modification of the active metal sites inside the zeolite, or competitive absorption between water and other reactants on the active sites. Many groups in the literature have proposed ways to improve the water stability of these materials, typically by building some bifunctional activity into the zeolite using multiple metal sites [2, 3]. However, these bifunctional 
materials tend to have drawbacks, either by having lower activity than the monometallic zeolite, or by being less selective towards $\mathrm{N}_{2}$ formation.

In this paper, we describe a different approach to building bifunctional catalysts using a metal-zeolite and a metal oxide. In our process, the oxide is added from a nano-particle sol, such that the oxide cannot enter the zeolite pores, and thus ends up as a coating on the outside of the zeolite. In this manner, the oxide can interact with the water before it enters the zeolite, as well as any other species, and thus prevent the water from interfering with the metal sites. Additionally, the oxide can provide some additional functionality by aiding in the various reaction mechanism steps or by forming a new phase when combined with the metal.

\section{EXPERIMENTAL}

\section{Synthesis}

Zeolites were provided by Zeolyst in their ammonium forms. Two basic methods were used to prepare the bifunctional materials.

(1) Ion exchange - Metals were added to the zeolite using ion exchange methods. Typically a $0.01 \mathrm{M}$ solution of the parent metal salt was prepared, though the concentration could be modified to split the ion exchange across several steps in order to achieve a desired loading or exchange level. The solution and zeolite were added at a ratio of $10 \mathrm{~mL} / 1 \mathrm{~g}$ and stirred vigorously. In some cases, the $\mathrm{pH}$ was adjusted to 7.5-8 using a dilute ammonium hydroxide solution (Fisher). The stirring was allowed to continue for at least $12 \mathrm{hrs}$. After the exchange, the material was filtered, rinsed with water, dried, then calcined at $500^{\circ} \mathrm{C}$.

(2) Impregnation - Metal oxide was added by incipient wetness impregnation of a nanoparticle sol (Nyacol, $20 \mathrm{wt} \%$ of oxide, 20-nm particles stabilized by acetate) on the zeolite, diluting the sol as necessary to achieve the desired loading level. After drying, the solid sample was calcined at $500^{\circ} \mathrm{C}$. Additional impregnations were performed to achieve higher loadings.

The order of these steps could be varied, but typically two processes were examined: one in which the metal was exchanged on the zeolite, followed by metal oxide impregnation, and one in which the metal oxide was added first, followed by the metal. Materials made in these fashions were called "forward" and "reverse" materials, respectively. In general, these materials are referred to as $\left(\mathrm{MIIO}_{\mathrm{x}}\right) / \mathrm{Ml}-\mathrm{Z}$, where $\mathrm{MI}$ is the exchanged metal, MII the metal oxide, and $Z$ the zeolite phase. Besides the bifunctional materials, samples of the metal-exchange only were made (M$Z$ ) as well as samples where only the oxide impregnation was performed $\left(\mathrm{MO}_{\mathrm{x}} / \mathrm{Z}\right)$. These singlephase materials were generally taken as a portion of the intermediate samples prepared by the forward and reverse synthesis procedures, such that $\mathrm{CeO}_{2} / Z \mathrm{ZSM}-5$ could be considered as the parent material of the reverse $\mathrm{CeO}_{2} / \mathrm{Cu}$-ZSM- 5 sample, for example.

Several metals were examined as provided by $\mathrm{Cu}\left(\mathrm{NO}_{3}\right)_{2}, \mathrm{Co}\left(\mathrm{NO}_{3}\right)_{3}, \mathrm{Ag}\left(\mathrm{NO}_{3}\right)$ and $\mathrm{Fe}\left(\mathrm{NO}_{3}\right)_{3}(\ldots)$, while $\mathrm{CeO}_{2}$ and $\mathrm{ZrO}_{2}$ were considered as the main oxides. Numerous zeolite phases (ZSM-5, Beta, MOR, FER, and $Y$ ) were examined with various $\mathrm{SiO}_{2} / \mathrm{Al}_{2} \mathrm{O}_{3}$ ratios (from 280 to 20). Primary focus was on the bifunctional catalyst system $\mathrm{CeO}_{2} / \mathrm{Cu}$ ZSM-5 with a $\mathrm{SiO}_{2} / \mathrm{Al}_{2} \mathrm{O}_{3}$ ratio of 50 . The metal was nominally added to achieve $100 \%$ exchange of the $\mathrm{Al}^{+}$sites, and the oxide loading of $20 \mathrm{wt} \%$.

\section{HC-SCR Reaction}

A microscale plug flow reactor was used to test the catalyst activity. Gas flow rates [He (99.995\%), $5 \% \mathrm{O}_{2}$ in $\mathrm{He}, 5 \% \mathrm{NO}$ in $\mathrm{He}$, and $3 \% \mathrm{C}_{3} \mathrm{H}_{6}$ in $\left.\mathrm{He}\right]$ were controlled using Brooks $5860 \mathrm{e}$ mass flow controllers to achieve a nominal gas concentration of $2 \% \mathrm{O}_{2}, 1000 \mathrm{ppm} \mathrm{NO}$ and 1000 ppm $\mathrm{C}_{3} \mathrm{H}_{6}$, with the balance $\mathrm{He}$ at $100 \mathrm{cc} / \mathrm{min}$. When used, water was introduced through a syringe pump as to achieve $10 \%$ by volume in the reactant feed; all lines after water introduction were heat traced to prevent condensation. The sample mass was typically 150 $\mathrm{mg}$, diluted up to $2 \mathrm{~g}$ using SiC (Electrochem Abrasives) in order to thicken the bed to avoid channeling and other transport effects. Reactor temperatures between 150 and $600^{\circ} \mathrm{C}$ were examined.

The effluent from the reactor was monitored using two detectors. An MTI MicroGC 200 with a Molecular Sieve 5A and a PoroPak $U$ column were used to identify the stationary gases $\left(\mathrm{O}_{2}, \mathrm{~N}_{2}, \mathrm{CO}\right.$, $\mathrm{CH}_{4}, \mathrm{CO}_{2}, \mathrm{~N}_{2} \mathrm{O}, \mathrm{C}_{2} \mathrm{H}_{2}, \mathrm{C}_{2} \mathrm{H}_{4}, \mathrm{C}_{2} \mathrm{H}_{6}, \mathrm{C}_{3} \mathrm{H}_{6}$ and $\mathrm{C}_{3} \mathrm{H}_{8}$ ). The $\mathrm{NO}$ and $\mathrm{NO}_{2}$ concentrations were monitored using a California Analytical Instruments NOx detector with a heated pump to prevent water condensation inside the instrument. Using both instruments allowed us to quantity the amount of side products $\left(\mathrm{CO}, \mathrm{N}_{2} \mathrm{O}\right.$ and $\mathrm{NO}_{2}$ ) that could potentially be produced by the $\mathrm{HC}$-SCR reaction. 
Prior to reaction, catalyst samples were flushed with $\mathrm{He}$ at $500^{\circ} \mathrm{C}$. It was found that generating a carbon layer on these materials drastically improved the activity at low temperatures, thus the HC-SCR reaction was run for at least $2 \mathrm{hrs}$ at $250^{\circ} \mathrm{C}$ prior to temperature changes in order to form the carbon layer, as observed by visual inspection of the catalyst and approach to pseudo-steady-state conditions.

\section{RESULTS AND DISCUSSION}

The catalytic activities of four representative samples under wet and dry HC-SCR conditions are shown in Fig. 1. In general, these materials follow the trends normally seen for HC-SCR catalysts; NO conversion increases along with hydrocarbon conversion with increasing temperatures, but once the temperature where nearly $100 \%$ conversion of the hydrocarbon is reached, the NO conversion begins to drop. This step is usually accompanied by the formation of $\mathrm{NO}_{2}$ in small amounts.

The Cu-ZSM-5 sample shows activity comparable to that reported in the literature. The maximum NO conversion was about $80 \%$ at $400^{\circ} \mathrm{C}$ under dry conditions, but dropped to $60 \%$ when water was present. The propylene conversion was near $100 \%$ at these conditions, but did produce a considerable amount of $\mathrm{CO}$ at lower temperatures. Very little $\mathrm{N}_{2} \mathrm{O}$ or $\mathrm{NO}_{2}$ was observed at $400^{\circ} \mathrm{C}$, though $\mathrm{NO}_{2}$ was more prevalent at higher temperatures. The loss of activity when Cu-ZSM-5 is exposed to a wet reactant feed, particularly under short-term conditions, suggests that water interferes

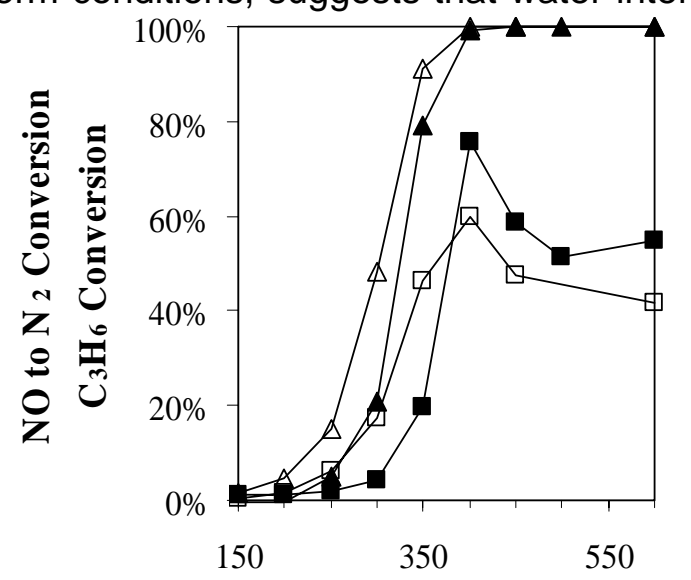

Temperature $\left({ }^{\circ} \mathrm{C}\right)$

(A) Cu-ZSM-5 with the HC-SCR reaction either through competitive absorption with the reactants or by altering the active ionic sites into oxide species, rather than damaging the zeolite structure.

On the other hand, the bifunctional materials showed significant changes in their HC-SCR behavior. Under dry conditions, the materials were not as active as Cu-ZSM-5, with about 30\% NO conversion, but their maximum activity was seen at a slightly lower temperature. No $\mathrm{N}_{2} \mathrm{O}, \mathrm{NO}_{2}$, or $\mathrm{CO}$ was seen in the effluent. When water was present in the system, however, the maximum NO conversion shifted to even lower temperatures (as low as $250^{\circ} \mathrm{C}$ ) and there was an increase in the conversion amount, up to $40-45 \%$. There was no formation of the side products either under wet conditions, thus making these catalysts highly selective towards $\mathrm{N}_{2}$ formation. At higher temperatures under both wet and dry conditions, the activity drop as previously noted, and there is a larger amount of $\mathrm{NO}_{2}$ formed compared with the $\mathrm{Cu}$ ZSM-5 catalyst. The forward sample had the most drastic temperature shift (about $100^{\circ} \mathrm{C}$ ) under wet conditions compared with Cu-ZSM-5 but also the lowest activity, while the reverse sample showed activity comparable to Cu-ZSM-5 but with only a $50^{\circ} \mathrm{C}$ temperature shift. Thus, there are significant changes in the catalytic sites on the forward and the reverse sample that lead to competing effects (higher activity versus lower operating temperatures).

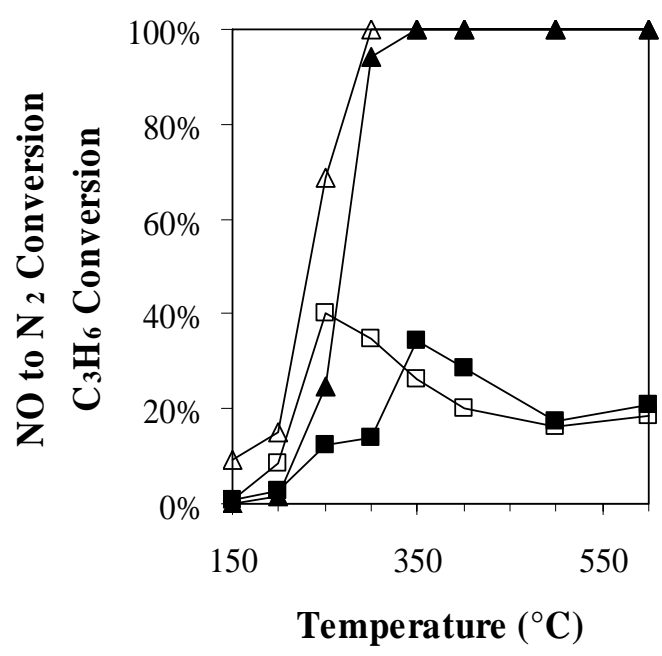

(B) metal oxide/Cu-ZSM-5

FIGURE 1 - NO to $\mathrm{N}_{2}$ conversion (squares) and $\mathrm{C}_{3} \mathrm{H}_{6}$ conversion (triangles) during dry (closed) and wet (open)

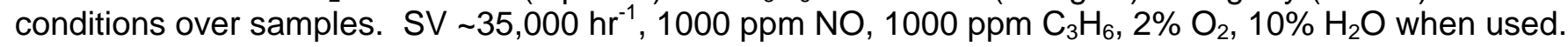


To verify the usability of these materials for the HCSCR at the industrial scale, space velocities tests were performed to determine where NO conversions between 80 and $90 \%$ would be met under wet operating conditions, as shown in Fig. 2 . For the Cu-ZSM-5 sample, effective NO reduction would occur at a space velocity of about $10,000 \mathrm{hr}^{-1}$ at a temperature of $350^{\circ} \mathrm{C}$. The forward bifunctional sample would require the same space velocity, but at $250^{\circ} \mathrm{C}$, to meet the NO reduction requirements, while the reverse sample would be able to achieve the same at $8,000 \mathrm{hr}^{-1}$ at $300^{\circ} \mathrm{C}$. Both bifunctional catalysts appear to be better than the Cu-ZSM-5 for the $\mathrm{HC}-\mathrm{SCR}$ reaction at meeting the desired NO remediation needs.

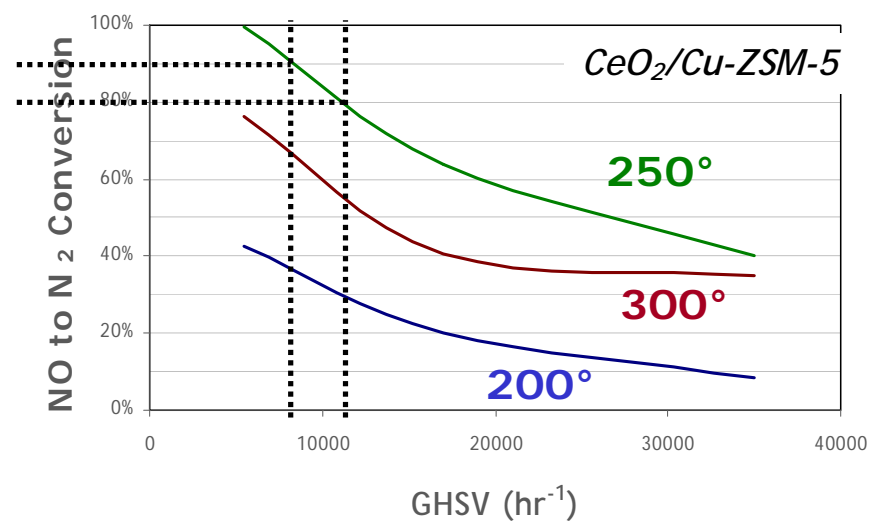

FIGURE 2 - Conversion versus space velocity at three temperatures.
Several other bifunctional systems were prepared and tested similarly to the $\mathrm{CeO}_{2} / \mathrm{Cu}-\mathrm{ZSM}-5$ system. The maximum NO conversions and temperatures for these materials, as well as the metal-exchanged parent materials, are listed in Table 1. Materials with the late transition metals ( $\mathrm{Co}, \mathrm{Cu}, \mathrm{Ag}$ ) exchanged on the zeolite appeared to have benefits similar to those with the $\mathrm{CeO}_{2} / \mathrm{Cu}$ ZSM-5 system, while early transition metals did not show appreciable benefits. A 1:1 mixture of $\mathrm{Cu}$ and Co along with $\mathrm{CeO}_{2}$ showed excellent performance under wet conditions. This follows the general literature trend that only the late transition metals have the appropriate absorption and chemical properties to be useful in the HC-SCR reaction. While $\mathrm{ZrO}_{2}$ alone as the metal oxide phase did not provide as strong a change in catalytic behavior as $\mathrm{CeO}_{2}$, a mixture of $\mathrm{ZrO}_{2}$ and $\mathrm{CeO}_{2}$ showed additional benefit. Given that mixtures of the rare earth and early transition metal oxides can be prepared to alter oxygen storage capacities, there may be additional multi-metallic oxides that could be used in this bifunctional material to further improve the catalyst. Of the zeolites, those with more openpore networks such as ZSM-5, mordenite, and ferrierite were components of bifunctional materials with the observed water enhancement features, while the narrow pore zeolites of Beta and $Y$ were not very effective for this reaction.

Table 1. Activity for Various Exchanged Zeolites

\begin{tabular}{|c|c|c|c|c|}
\hline & \multicolumn{2}{|l|}{ Dry } & \multicolumn{2}{|c|}{ Wet } \\
\hline Sample & Maximum NO to $\mathrm{N}_{2}$ Conv. & Temperature $\left({ }^{\circ} \mathrm{C}\right)$ & Maximum $\mathrm{NO}$ to $\mathrm{N}_{2}$ Conv. & Temperature $\left({ }^{\circ} \mathrm{C}\right)$ \\
\hline \multicolumn{5}{|l|}{ Cu-ZSM-5 } \\
\hline \multicolumn{5}{|l|}{$\mathrm{CeO}_{2} / \mathrm{Cu}-\mathrm{ZSM}-5$} \\
\hline Co-ZSM-5 & 30 & 550 & 25 & 500 \\
\hline $\mathrm{CeO}_{2} / \mathrm{Co}-\mathrm{ZSM}-5$ & 32 & 450 & 47 & 400 \\
\hline Fe-ZSM-5 & 18 & 450 & 14 & 400 \\
\hline $\mathrm{CeO}_{2} / \mathrm{Fe}-\mathrm{ZSM}-5$ & 18 & 400 & 16 & 350 \\
\hline Ag-ZSM-5 & 25 & 600 & 18 & 600 \\
\hline $\mathrm{CeO}_{2} / \mathrm{Ag}-\mathrm{ZSM}-5$ & 35 & 500 & 27 & 400 \\
\hline Cr-ZSM-5 & 17 & 450 & 7 & 600 \\
\hline $\mathrm{CeO}_{2} / \mathrm{Cr}-\mathrm{ZSM}-5$ & 10 & 400 & 8 & 400 \\
\hline Y-ZSM-5 & 10 & 350 & 0 & $\mathrm{~N} / \mathrm{A}$ \\
\hline $\mathrm{CeO}_{2} / \mathrm{Y}-\mathrm{ZSM}-5$ & 20 & 600 & 18 & 550 \\
\hline $\mathrm{CeO}_{2} /(\mathrm{Cu}, \mathrm{Co})-\mathrm{ZSM}-5$ & 25 & 450 & 47 & 400 \\
\hline $\mathrm{ZrO}_{2} / \mathrm{Cu}-\mathrm{ZSM}-5$ & 42 & 500 & 45 & 450 \\
\hline$\left(\mathrm{CeO}_{2}, \mathrm{ZrO}_{2}\right) / \mathrm{Cu}-\mathrm{ZSM}-5$ & 35 & 450 & 42 & 400 \\
\hline Cu-MOR & 62 & 350 & 27 & 350 \\
\hline $\mathrm{CeO}_{2} / \mathrm{Cu}-\mathrm{MOR}$ & 55 & 350 & 30 & 300 \\
\hline Cu-FER & 78 & 400 & 52 & 350 \\
\hline $\mathrm{CeO}_{2} / \mathrm{Cu}-\mathrm{FER}$ & 72 & 400 & 52 & 350 \\
\hline Cu-BETA & 56 & 500 & 32 & 450 \\
\hline $\mathrm{CeO}_{2} / \mathrm{Cu}-\mathrm{BETA}$ & 50 & 500 & 30 & 450 \\
\hline $\mathrm{Cu}-\mathrm{Y}$ & 20 & 550 & 10 & 500 \\
\hline $\mathrm{CeO}_{2} / \mathrm{Cu}-\mathrm{Y}$ & 17 & 450 & 15 & 400 \\
\hline
\end{tabular}




\section{CONCLUSION}

A series of bifunctional catalysts composed of a metal-exchange zeolite with a metal oxide layer strictly on the outside of the zeolite have been prepared and shown to be excellent materials for the selective catalytic reduction of NO using propene as a reductant. The use of a nano-particle sol for the oxide source provides a method for preventing the insertion of the oxide inside the zeolite pore. Characterization of the materials by various means shows that these particles adhere to the external zeolite surface, and possibly form a mixed oxide phase with the exchanged metal on the external surface; this mixed oxide phase (???) can be easily reduced at low temperatures. The placing of the oxide and the formation of this mixed oxide phase leads to lower-temperature $\mathrm{HC}$-SCR reduction compared with the metal-zeolite only, and more importantly, activity enhancement when water is present in the reactant feed. The bifunctional catalysts appear to be strong candidates for the HCSCR reaction in order to meet the pending requirements for $\mathrm{NO}$ emissions reduction.

\section{ACKNOWLEDGMENTS}

This work was supported by the U.S. Department of Energy under contract number W-31109-ENG-38. Use of the Advanced Photon Source (APS) was supported by the U.S. Department of Energy, Basic Energy Sciences, Office of Science, under Contract No. W-31-109-Eng-38. Work performed at the APS MR-CAT is supported, in part, by funding from the U.S. Department of Energy under grant number DEFG0200ER45811. Additional funding support was provided by the BP Corporation.

\section{REFERENCES}

1. Zhang, W., Yahiro, H., Mizuno, N., Izumi, J., and Iwamoto, M., 1992, "Removal of Nitrogen Oxides (NOx) by Pressure Swing Adsorption. 1. Adsorption-Desorption Properties of Nitrogen Monoxide on Metal Ion-Exchanged Zeolites," Chemistry Letters, 5, pp. 851-854.

2. Arai, H. and Machida, M., "Removal of NOx Through Sorption-Desorption Cycles Over Metal Oxides and Zeolites," Catalysis Today, 22, 97-110.

3. Tabata, T., Kokitsu, M., and Okada, O., 1994, "Adsorption Properties of Oxygen and Methane on Ga-ZSM-5; The Origin of the Selectivity of NOx Reduction using Methane," Catalysis Letters, 25, 393-400. 